\title{
Accent Bias and Perceptions of Professional Competence in England
}

\author{
Erez Levon (University of Bern) \\ Devyani Sharma (Queen Mary University of London) \\ Dominic Watt (University of York) \\ Amanda Cardoso (University of British Columbia) \\ Yang Ye (University of Greenwich)
}

\begin{abstract}
Unequal outcomes for individuals from less privileged backgrounds in professional hiring have been widely reported in England. Although accent is one of the most salient signals of such a background, the role of accent in unequal professional outcomes remains under-examined. This paper reports on a large-scale study of contemporary attitudes to accents in England. A large $(n=848)$ representative sample of the population in England judged the interview performance and perceived hirability of "candidates" for a trainee solicitor position at a corporate law firm. Candidates were native speakers of one of five English accents stratified by region, ethnicity and class. Results suggest persistent patterns of bias against certain accents in England, particularly Southern working-class varieties, though moderated by factors such as listener age, content of speech and listeners' psychological predispositions. We discuss the role that the observed bias may play in perpetuating social inequality in England, and encourage further research on the relationship between accent and social mobility.
\end{abstract}

Keywords: Accents, bias, language attitudes, England, social mobility, sociolinguistics 
It is impossible for an Englishman to open his mouth without making some other Englishman hate or despise him.

- George Bernard Shaw, Pygmalion, 1916

\section{Introduction}

Social mobility is widely considered to be stagnant in the UK (Social Mobility Commission 2019, 2020; The Sutton Trust and Social Mobility Commission 2019). Despite repeated government commitments to tackle the issue (Cabinet Office 2011; Mason 2013; Baxter 2016; Coates 2016), research has demonstrated that upward income mobility in Britain has declined over the past 50 years (e.g., Blanden, Goodwin, Gregg, Machin \& Corak 2004; Blanden, Gregg \& Machin 2005); that elite professions like law and medicine continue to be dominated by people from socially and economically privileged backgrounds (Friedman, Laurison \& Miles 2015; Wakeling \& Savage 2015; Buscha \& Sturgis 2018); and that the social status of one's family remains the strongest predictor of attained levels of wealth, education and asset ownership in the UK (Clark \& Cummins 2013; Clark 2014).

As accent is a key signal of an individual's social background, we can expect attitudes about language to play a part in perpetuating these patterns of inequality. A survey by the Chartered Institute of Personnel and Development (2006), for example, found that over 76\% of UK employers admitted to discriminating against job applicants on the basis of their accents, and only $3 \%$ of employers nationally include accent or dialect differences as a protected category. Relatedly, a recent study commissioned by the Social Mobility Commission (Ashley, Duberley, Sommerland \& Scholarios 2015) determined that working class candidates are often unable to gain access to elite employment sectors despite having the relevant qualifications and skills because of informal "poshness tests", including a 
candidate's style of speaking. Yet despite all of this, the relationship between accent and social mobility in the UK remains largely unexplored. Most studies of bias in professional recruitment in the UK have not focused on the specific role of accent, and studies of accent bias have not tended to focus on employability or language attitudes in a professional context. There thus exists a crucial need to examine the specific role of accent bias at key junctures of social mobility, such as access to employment.

Addressing this need is the principal objective of the Access Bias in Britain (ABB) project (Levon, Sharma \& Watt 2017-2021), which aims to provide a nuanced account of contemporary attitudes to current accents in the UK and to assess how these attitudes may act as impediments to professional advancement. The project involves a number of different experimental studies, including investigations of attitudes to both accent labels and audio speech samples and among various listener populations (general public and expert listeners). In this article, we focus on just one component of this work, and report results from a large nationwide survey among the general public of perceptions of the suitability of speakers of five British accents for a job in the legal sector. We do so in order to identify the broader cultural context of accent attitudes in Britain in relation to employment in an elite profession, like law. Prior research has clearly demonstrated that discriminatory outcomes in access to elite professions is based on a perceived "cultural mismatch" between group stereotypes (i.e., beliefs about the social group that a job candidate belongs to) and role stereotypes (i.e., beliefs about the type of person who normally occupies a given professional role) (Eagly \& Diekman, 2005; Stephens, Townsend \& Dittmann, 2019). Examining whether a candidate's accent contributes to this kind of perceptual mismatch among the general public provides us with crucial information about the content of the relevant group and role stereotypes, and hence is an important first step in determining the extent to which accent attitudes may impede access to professional employment (cf. Kraus, Torrez, Park \& Ghayebi 2019). 
In this article, we demonstrate that accent bias among the UK general public exists. Based on evaluations of speakers' performances in mock job interviews, speakers of certain accents are judged as less suitable for professional employment than others, despite identical content in their responses. We also show, however, that this bias is more nuanced and subtle than has been previously reported (Baratta 2015; Kraus, Torrez, Park \& Ghayebi 2019). We discuss the ramifications of our findings both for the sociolinguistic study of accent bias and for broader questions about the role that language ideologies may play in perpetuating social inequality. We begin in the next section with a brief overview of research to date on accent bias in the UK and elsewhere. We then turn to a discussion of our survey methods and findings, before concluding with a discussion of the broader implication of our results.

\section{Studying Accent Bias}

Most research into bias in hiring in the UK has focused on general social factors such as ethnicity and schooling, not accent. Heath and Cheung (2006) found worse outcomes for ethnic minority groups in terms of employment, rate of pay, and level of work attained, even while keeping education profile and age constant. In a field experiment, Wood, Hales, Purdon, Sejersen and Hayllar (2009) submitted matched job applications and confirmed a significant ethnic bias, with greater evidence of bias in private rather than public sector employment. Friedman, Laurison and Miles (2015) investigated data from the BBC's Great British Class Survey of 325,000 British residents (Savage et al. 2013; Devine \& Snee 2015) to reveal that even once they access elite employment, people from socially and/or ethnically marginalized backgrounds end up accumulating less economic and cultural capital over their lifetimes than their colleagues and peers who had more privileged upbringings.

It is well-known that accent, particularly in the UK, encodes many of the social contrasts (e.g., ethnicity, parental social class, region of origin) upon which these differences 
in attainment are based. For centuries, accent and dialect have played a central role in structuring British society and determining socioeconomic prospects (e.g., Swift 1712; Shaw 1916; Fox 2004; Mugglestone 2007; Fry 2011; Toynbee 2011). This constitutive role of accent in signaling class and education in the UK has fostered dangerously inaccurate public discourse about the language of minority groups and fueled discriminatory stereotypes about speakers of non-standard varieties. Accent may thus be a key contributor to the patterns of employment bias that have been observed, and so play a part in perpetuating unequal access in Britain. Yet this link remains under-investigated.

Research in sociolinguistics has examined subjective perceptions of a range of British accents, though these observations have rarely been tied to bias in hiring. In a series of early studies, Giles (1970, 1973) and Powesland and Giles (1975) demonstrated that Received Pronunciation (RP), the national standard British accent, is perceived by listeners in the UK as having higher status than other urban and regional varieties. They also found that political arguments presented in RP are heard as more persuasive and of better quality than arguments in distinctive local varieties. In more recent work, Garrett, Coupland and Williams (1999), Bishop, Coupland and Garrett (2005) and Coupland and Bishop (2007) identified systematic preferences for certain accents and corresponding dispreferences for others. Standard accents and accents associated with higher socioeconomic status, in particular RP, were perceived as being more prestigious and educated, although they were often rated less positively for traits like pleasantness and friendliness. Conversely, non-standard accents (often urban, workingclass accents, though also some rural, regionally distinctive accents) were rated positively with regard to likeability and friendliness but were not perceived to signal educatedness and other indicators of prestige and status. Together, these studies have indicated a persistent hierarchy of accent prestige in the UK, with RP and other standard accents at the top and urban non-standard varieties at the bottom. 
Unlike the early work of Giles and colleagues, these more recent studies of attitudes to a wide cross-section of UK accents have tended to adopt a conceptual approach, examining respondent reactions to dialect labels (e.g., "Queen’s English”, "Birmingham”) rather than having listeners respond to actual audio stimuli. Studies of accent labels are useful in allowing us to identify the "broad language-ideological structures that are a backdrop to accent encounters" in the UK (Coupland and Bishop 2007:86). Yet it is nevertheless important to bear in mind that attitudes to ideological constructs, like accent labels, may not directly parallel attitudes to real-world examples of accent variation. Giles (1970), for instance, notes that respondents provide different ratings for accent labels than they do for verbal stimuli, and Bishop, Coupland and Garrett (2005) caution that evaluations of accent concepts rely on deeply conservative language ideologies that may obscure the more finegrained attitudes that emerge in situated contexts of language use. A focus on accent labels in recent UK-based attitudes research may therefore have over-estimated the persistence of a rigid hierarchy of accent evaluations across the country.

This is not to say that there have been no recent studies examining reactions to real speech in the UK. But these studies have tended to look at attitudes to individual varieties (e.g., Received Pronunciation; Fabricius 2005) or to consider the extent to which isolated features of accents are heard as distinctive (e.g., Llamas, Watt \& Johnson 2009; Watson \& Clark 2013; Levon \& Fox 2014; Levon \& Buchstaller 2015; Montgomery \& Moore 2018; Kircher \& Fox 2019). A notable exception is Hiraga (2005), which examines the evaluative reactions of 32 British listeners to three British accents: Received Pronunciation, Birmingham and (rural) West Yorkshire (Hiraga also collected reactions to three American English accents that represented an analogous standard $\sim$ urban $\sim$ rural taxonomy). After hearing “neutral” sound clips taken from the International Dialects of English Archive (IDEA), listeners rated the accents on a series of semantic differential scales that were designed to 
elicit judgments of speaker status and likeability. Hiraga finds that evaluations parallel the results of Giles (1970) from 35 years before: RP is top-ranked for status, followed by (rural) West Yorkshire and (urban) Birmingham. When examining status and likeability together, Hiraga discovers the same basic hierarchy, with RP on top and regional and urban varieties ranked lower. Hiraga uses this finding to argue in favor of the imposed norm hypothesis (Giles, Bourhis, Trudgill \& Lewis 1974), whereby standard varieties - by virtue of their high status - are ideologically imagined as being not only the most correct, but also the most aesthetically pleasing and, hence, the most likeable.

Given Hiraga's (2005) result, and the consistency in perceptions of accent variation across decades, we anticipate that, for those seeking positions in elite professions, an ability to speak with a standard (i.e., RP) or close-to-standard accent (i.e., Standard Southern British English, SSBE) would be seen as highly advantageous. To date, this prediction has not been tested with a large sample and audio stimuli of professional speech. Some early matchedguise studies explored character traits of professional suitability for individual accents. For example, Giles, Baker and Fielding (1975) found that even when all other aspects of communication are kept 'standard' (grammar, lexis, speaking style), high school students judged a speaker with a Birmingham accent to be less intelligent and less appropriate for a job as a university lecturer than an RP speaker (see also Dixon, Mahoney \& Cocks 2002). Similarly, Kalin, Rayko and Love (1980) found that English English was preferred in employment interviews over (standard) West Indian English, while Giles, Wilson and Conway (1981) reported that the lowest status jobs were seen as most suitable for speakers with non-standard accents (see Alemoru 2015 for a more recent study of these effects in relation to Multicultural London English). In addition to this quantitative work, a number of qualitative studies have also noted discrimination against non-standard and/or non-native accents in the workplace even when comprehension and communicative effectiveness are not 
at issue (e.g., Roberts, Davies \& Jupp 1992), as well as self-suppression of regional accents for employment purposes (Baratta 2017, 2018). However, many of these studies, particularly those adopting quantitative approaches, were conducted more than a decade ago, and there have been few systematic comparative examinations of attitudes to multiple accents as currently spoken in contemporary Britain. There is therefore an urgent need for an updated picture of current attitudes to audio samples of accents in the UK, and the role these attitudes could subsequently play in affecting professional outcomes. This is our focus in the present paper.

\section{Methods}

We conducted a verbal guise study (Cooper \& Fishman 1974; Cooper 1975) to examine listeners' evaluative responses to five English accents in a professional employment context:

- Received Pronunciation (RP; Ellis 1869; Jones 1937; Collins \& Mees 1999; Fabricius 2000; Badia Barrera 2016);

- Estuary English (EE; Altendorf 2003);

- Multicultural London English (MLE; Cheshire, Fox, Kerswill \& Torgersen 2008; Cheshire, Kerswill Fox \& Torgersen 2011);

- General Northern English (GNE; Watt 2002; Beal 2009; Strycharczuk, López-Ibáñez, Brown \& Leemann 2020);

- Urban West Yorkshire English (UWYE; Beal 2004).

These five accents are chosen because together they allow us to examine listener evaluations across a number of fundamental social contrasts. These include region (EE and MLE in the south of England vs. GNE and UWYE in the north), prestige (RP and GNE as "standard" 
accents vs. EE, MLE and UWYE as "non-standard"), localness (MLE and UWYE as local, EE and GNE as supralocal, RP as national), age (e.g., MLE and GNE as more recently emergent varieties) and ethnicity and class (e.g., UWYE and EE as stereotypically white working class, MLE as stereotypically multi-ethnic working class). The five accents also differ across a range of linguistic features including: the presence and prevalence of $/ \mathrm{t} / \mathrm{-}$ glottaling, ING fronting, /h/-dropping, TH-fronting, TH-stopping, and /l/-vocalization; the realization of laterals and rhotics; the realization of the monophthongs in the STRUT, BATH, FOOT, and GOOSE lexical sets, as well as that of the diphthongs in the MOUTH, FACE, GOAT, and PRICE lexical sets, to name just a few. A selection of the differences across accents are listed in Table 1.

\section{TABLE 1}

Examples of Distinctive Features across the Five Accents Tested

\section{[TABLE 1 HERE]}

To create the verbal stimuli for the survey, we recorded ten young men (all between the ages of eighteen and twenty-five) who were each a native speaker of one of the five accents (two speakers per accent, to check for speaker-specific effects). The men were all professional actors or, in the case of the MLE speakers, professionals in finance and entertainment. They were recorded in a soundproof recording studio. We restrict ourselves to men so as to avoid any potential confounding effects of gender stereotypes (e.g., Trudgill 1974; Grondelaers, van Hout \& van Gent 2018) or differences in how listeners evaluate women versus men as dialect speakers (Fabricius 2006), and we record young men so as to mimic the expected age of entry-level law firm candidates. 
The stimuli they performed were mock responses to ten different sample legal interview questions (see Levon, Sharma \& Watt 2020 for all stimulus texts used). We focus on this particular context since we are interested in exploring whether accent may impede social mobility and professional advancement. As prior work in both linguistics and psychology has demonstrated, attitudes to language and other forms of socially meaningful practice are contextually situated, such that the evaluation of a behavior in one context does not necessarily apply in another (Gawronski, Ye, Rydell \& De Houwer 2014; Nayakakuppam, Priester, Kwon, Donovan \& Petty 2018; Hilton \& Jeong 2019; Levon \& Ye 2020). It is therefore not possible to assume that attitudes to language in a professional context will match those elicited in a more general (or "neutral") context (Ajzen 1991, 2005; Campbell-Kibler 2009). Instead, we must endeavor to solicit attitudes as they emerge within the particular social context of interest. With this in mind, we follow the example of previous studies of accent variation and access to employment (e.g., Pantos \& Perkins 2012) by designing our experiment to target the context of a legal employment interview specifically. We chose law as a classic example of an "elite" profession, and one for which disparities in access to employment in the UK have previously been reported (Ashley, Duberley, Sommerland \& Scholarios 2015).

The content of the response stimuli was developed in close consultation with lawyers on the project's advisory board, and covers a range of typical interview topics, including both those that require more technical legal expertise (five question-response pairs) and those about more general professional skills (five question-response pairs). Examples of technical and general question-response pairs are presented in (1) and (2), respectively. We included this content manipulation (expert versus non-expert) so as to test whether legal content interacts with accent-based judgments. Aware that we would ultimately be testing these stimuli among both expert and non-expert listeners, we were also careful to ensure that 
"expert" responses did not contain opaque legal terminology and would be generally accessible to a broad listening public. Our decision to compare reactions to expert versus non-expert content among the general public was inspired by studies such as Cargile, Giles, Ryan and Bradac (1994:220), which argued that situations in which non-expert listeners judge expert content may be precisely those where language attitudes play a more significant role:

Language attitudes could also be a central feature of processing when the hearer is not experienced with a particular sort of social encounter... A non-expert will possess less knowledge about and fewer schema for the situation. Consequently, he or she will most likely rely upon language attitudes to provide (supposed) information about the speaker. In this case, the use of language attitudes will not be the selective, constructive process it is with the involved expert. Rather, the available language behaviors will almost automatically cue attitudes in the hearer.

Written versions of all question-response pairs were pre-tested on a group of twenty lawyers otherwise unrelated to the project, who confirmed their naturalness and their objective quality. We aimed for responses that would be judged as neither very good nor very bad, since research in psychology has demonstrated that peripheral cues (like accent) play a more active role in determining evaluative judgments when the content to be evaluated is ambiguous (e.g., Chaiken \& Maheswaran 1994).

(1) Think about the 2008 recession. What effects do you think that had on us as a firm? There would have been less business overall for the firm, so that must have had various effects. Employees are expensive, so you might have thought about reorganizing both lawyers and support staff. You would have also thought about fixed 
costs, like the lease on the firm's main office. There would have been more competition for legal work from other firms, so you would have had to think about how many lawyers were assigned to deals, and how the deals were priced.

(2) Tell us of a time that you solved a problem.

We always had very interesting problem questions in my Business Law and Practice module on the LPC [Legal Practice Course: the postgraduate qualification required to become a practicing solicitor in the UK]. My group would meet to work through the material together. One problem in particular involved the incorporation of a company and how that's done at Companies House. I was the first to solve the problem, and I helped several of my classmates working through the problem. The lecturer commented that I'd manage well with problem-solving in practice, if I could spot issues on the LPC that quickly.

Each of the ten speakers recorded all ten of the mock responses, for a total of 100 stimuli for testing (audio stimuli are all available on Levon, Sharma \& Watt 2020). Stimuli were post-processed to remove any disfluencies or hesitation markers, to standardize intensity (at $70 \mathrm{~dB}$ ), and to ensure that mean pitch levels of all recordings were comparable. ${ }^{1} \mathrm{We}$ did not control for speaking rates across speakers, under the assumption that speech rate variation may itself be an accent/dialect feature (Ray \& Zahn 1990; Hewlett \& Rendall 1998; Jacewicz, Fox \& Salmons 2007). Recordings were pilot tested by presenting them to (i) ten linguists with expertise in British dialect variation to confirm that the recordings provided accurate representations of the five target accents; (ii) sixty-eight listeners from the UK general public to confirm that the two speakers for a given accent were evaluated similarly in terms of traits like perceived "masculinity" and "friendliness"; and (iii) an additional 130 
listeners from the UK general public to confirm that the content of the recordings was accessible and that the recordings themselves did not sound "fake" or "forced".

Stimuli were presented via an online Qualtrics survey to a representative sample of 848 adult members of the general public in England (ages 18-84, median age $=47$ ). In our broader project, evaluations were also collected from respondents in Northern Ireland, Scotland and Wales (for a total sample across the UK of $\mathrm{N}=1014$ ). We concentrate our analyses here on respondents in England only for two reasons. First, while we can assume some familiarity with the five target accents throughout the UK, prior research has shown that accents may be evaluated differently across the four constituent nations (e.g., Bishop, Coupland, and Garrett 2005; Sharma, Levon \& Ye, in press). This is due both to differing levels of contact with English accents outside of England and, more importantly, to the existence of different standard language markets in places like Scotland and Northern Ireland, where local national varieties (e.g., Scottish Standard English) compete for prestige with varieties from England (Milroy \& Milroy 1985). Second, because we sampled the UK population proportionally, there is an insufficient number of respondents in each of the four nations to allow for robust quantitative comparisons across them. While it would be possible to collapse Northern Ireland, Scotland and Wales into a single "non-England" comparator for statistical purposes, doing so would elide a great deal of social and linguistic heterogeneity across the three nations. We therefore choose to focus on respondents in England only $(\mathrm{N}=$ 848) and acknowledge limited generalizability to the rest of the UK (see Sharma, Levon \& Ye, in press for an examination of accent attitudes across the UK).

Respondents were recruited with the help of a professional market research firm so as to obtain a sample that matches the demographic distribution of the adult population in England with respect to gender, region and ethnicity (see Table 2). This allows us to obtain a representative snapshot of nationwide attitudes to accents. While not a sampling criterion, 
Table 2 also includes information about the median socioeconomic class of different subgroups of the listener population. We operationalize socioeconomic class as an index ranging from one (lowest) to nine (highest), calculated as an equally weighted average of a respondent's current occupation (using the standard occupational class categories devised by the UK Office for National Statistics) and a respondent's highest level of education (raw calculations of our Social Class Index are available at Levon, Sharma \& Watt 2020). Respondents were told that they would be completing a survey on how candidates are evaluated in a job interview, without any mention of accent. Respondents were required to complete the survey on a desktop computer, and were instructed to do so while wearing headphones and in a quiet room where they would not be interrupted for fifteen minutes. Respondents received compensation for their participation directly from the market research firm.

\section{TABLE 2}

Demographic Distribution of Respondents

[TABLE 2 HERE]

After completing consent procedures, respondents were shown a screen informing them that they would be hearing responses to interview questions for an entry-level position at a major UK law firm from ten different candidates. They were told that all candidates had completed the same preliminary legal training, and so were all equally qualified for the post. Following these general instructions, respondents completed a practice round in which they heard and rated an interview response from a North American speaker in order to familiarize themselves with the survey interface and the rating scales used, and to check their audio. After the practice round, respondents proceeded to rate all ten target candidates. We used a 
Latin square design in order to collect ratings of all 100 stimuli across the sample, while ensuring that no one respondent ever heard the same candidate or response twice. ${ }^{2}$ In other words, respondents each heard two examples of each of the five accents (i.e., two speakers per accent) providing answers to ten different questions.

For each candidate, the relevant interview question was first presented in writing at the top of the computer screen. Respondents were instructed to read the question, and, once they had finished reading, to play the corresponding audio response by pressing the play button of an on-screen media player. All stimuli were approximately twenty-seven seconds long. Stimuli could not be replayed, and needed to be listened to in full before respondents could move on to the next screen where they provided their ratings. After hearing each response, respondents were asked to rate the candidate on five ten-point scales that were designed to elicit evaluations of the candidate's knowledge and expertise, the likelihood they would succeed as a lawyer, the candidate's likeability, and the overall impression the candidate made. The specific wording of the rating scales is presented in Table 3.

\section{TABLE 3}

Evaluation Scales

[TABLE 3 HERE]

After rating all ten candidates, respondents provided basic demographic information, including their age, gender, region, ethnicity, level of education and occupation. They were also asked about their linguistic background: whether they spoke any other languages, how they would characterize their own accent in English, and whether they had been geographically and/or linguistically mobile in their lives. Finally, respondents completed short questionnaires about whether they believe there exists discrimination on the basis of 
social class and regional origin in the UK today, as well as on how important it is to them to appear non-prejudicial in their interactions with others. We provide further details about these social and psychological factors, where relevant, in the discussion of our findings below.

\section{Results}

Preliminary analyses of evaluations from respondents in England indicated that ratings on all five of the scales listed in Table 1 (overall response quality, expertise, likelihood to succeed, personal likeability, overall rating) were highly correlated $(\alpha=0.96)$. We therefore collapse the five ratings into one composite score, which we take to represent an average evaluation of how "hirable" a speaker sounds. Figure 1 depicts mean hirability ratings for each accent across the respondent population in England. The pattern across accents in Figure 1 broadly corresponds to what we would anticipate from prior research and popular stereotypes in the UK: RP receives the highest rating while EE and MLE receive the lowest. The differences between means are, however, fairly small, ranging from 6.75 (out of 10) for RP to 6.53 for EE, corresponding to a difference of $2.2 \%$ of the evaluative scale. This is somewhat surprising, as prior work has identified differences in average accent evaluations of as much as $40 \%$ (Hiraga 2005). These larger differences, however, have tended to be found in work soliciting reactions to "neutral" stimulus passages. Research that has looked at accents specifically in relation to perceptions of hirability has tended to find much smaller effects (e.g., Rakić, Steffens \& Mummendey 2011 found a difference in average ratings of 5\% in their investigation of perceived hirability and accent variation in German). We suggest that it is the hiring context itself that places a lower bound on respondent ratings, and potentially constrains the differences between accent evaluations overall.

Figure 1: Mean Accent Evaluations in England $(\mathrm{N}=848)$ 


\section{[FIGURE 1 HERE]}

We built linear mixed-effects regression models using the lme4 package (Bates, Mächler, Bolker \& Walker 2015) in R 3.6.1 (R Core Team 2019) to investigate the effect of accent and other social and psychological factors on respondents' evaluations, as listed in Table 4. The choice of which predictors to model was based on prior research and initial inspections of the dataset. ${ }^{3}$ Once candidate predictors were chosen, analyses began with maximal models that included all fixed effects and their interactions. Models were then manually stepped down to a final model (see Appendix) that includes only significant predictors and predictors that participate in significant interactions (as assessed by comparing model residual sums of squares). All models included random intercepts for speaker, question and their interaction (to account for our use of a Latin square design) as well as a random intercept for respondent and random slopes for respondent by accent and by question type (expert, non-expert) to account for the repeated measures structure of the survey (i.e., respondents each rating 10 stimuli, with each of 5 accents represented by 2 different speakers). This model design allows us to test the specific effect of accent on listener evaluations, independent of the particular speaker being rated or the specific question the speaker is responding to. Factor-level significance testing is based on t-tests using Satterthwaite approximations, as implemented in the lmerTest package (Kuznetsova, Brockhoff \& Christensen 2017). (For full model results, see the Appendix)

\section{Table 4}

Fixed-Effects Predictors for Regression Modelling [TABLE 4 HERE] 


\subsection{Accent Bias and Life Stage}

Despite the apparent differences in accent ratings in Figure 1, and what both popular beliefs and the prior research outlined above might lead us to expect, regression analyses reveal no significant main effect of accent on listener evaluations $(F(4,5.4)=0.356, p=0.829)$. This is not to say that listeners are not sensitive to accents at all. But rather than a simple main effect of accent on listener ratings, we find instead a series of complex interactions between accent and other factors that constrain listeners judgments of speaker "hirability". We discuss each of these interactions in turn and why our findings may differ from studies of accent attitudes in other (i.e., non-professional) contexts.

The most prominent result of our analyses is an interaction between age and accent. There exists a general negative correlation in the data between age and listener evaluations $(\mathrm{F}(1,823.5)=23.783, \mathrm{p}<0.001)$. As respondents get older, they rate candidates more negatively overall, dropping from an average rating of 7.12 at age 25 to 6.4 at age 55 . Yet, as illustrated in Figure 2, this age effect further interacts with accent $(F(4,3182.8)=4.901$, $p<$ 0.001), such that younger respondents $(<45)$ show no significant differences in rating across accents, whereas older respondents $(>45)$ do. Post-hoc tests reveal that for older respondents, speakers of EE and MLE are significantly downgraded for perceived hirability as compared to speakers of RP, GNE and UWYE. In other words, respondents who are over 45 years old judge candidates speaking with urban non-standard working-class accents from Southern England (EE and MLE) to be less suitable for entry-level employment in a law firm than they do candidates with Northern accents (GNE and UWYE) or candidates who speak the national standard (RP). Respondents under the age of 45, in contrast, make no such distinction.

While it may be tempting to interpret this result as evidence of a generational change in societal beliefs about accents, previous studies have found similar significant interactions between listener age and evaluations of accent prestige. In their survey of accent labels 15 
years ago, Coupland and Bishop (2007) reported that ratings of the prestige of $A$ standard accent of English (their version of RP) were positively correlated with age, with respondents aged 45 and above evaluating this accent label significantly more positively than respondents under the age of 45. Coupland and Bishop also noted significant age effects for ratings of the labels Afro-Caribbean and Asian on the prestige dimension, whereby older respondents evaluate these accent labels more negatively than younger respondents do (see also our replication of Coupland and Bishop's labels study; Sharma, Levon \& Ye, in press). ${ }^{4}$ Though they focus on general attitudes to accent labels rather than heard speech, Coupland and Bishop's (2007) results parallel those of the current survey, and point to the age of 45 as a sort of evaluative threshold in which distinctions between standard and non-standard accents become apparent. Likewise, Giles (1970) notes an age difference among his respondents, with older listeners associating RP with significantly more prestige than younger listeners do. It is important to note that all of Giles' respondents are very young, varying between the ages of 12 and 17, meaning that the age effect that Giles reports is qualitatively very different than the effect at issue in the current study. Nevertheless, Giles (1970:219) argues that the difference could be indicative of the "older adolescents ... moving more in the direction of conventional social evaluation", though he also concedes that "only a longitudinal study could test the hypothesis that these age differences are stable."

Figure 2: Accent Evaluations by Age (Model Predicted Values) [FIGURE 2 HERE]

Our results provide precisely this type of longitudinal evidence. Fifty years after Giles' (1970) study, and 15 years after Coupland and Bishop's, we identify a convergent result in which older respondents display more bias in their judgments of accent prestige in a 
professional context by demonstrating a dispreference for Southern working-class varieties, while younger respondents show no such effect. Given the similarity of these age-linked findings across decades, we argue that the interaction between age and accent evident in Figure 2 does not reflect a pattern of generational change, but rather one of age-grading. We suggest that as people become more embedded in workplace norms of standard language, their evaluations of what constitutes an appropriate accent for professional employment become more rigid and “old-fashioned” (to borrow Giles' 1970:219 term), allowing biased language attitudes to emerge. Age thus functions as a proxy for differences in life stage (e.g., Eckert 1997; Sankoff \& Blondeau 2007), revealing a difference between older adults who conform more closely to pressures of a standard language marketplace and younger adults who orient to a broader and more diverse set of language norms (cf. discussions of the 'adolescent peak', Labov 2001; Tagliamonte and D’Arcy 2009). Importantly, this pattern is orthogonal to differences in social class in our dataset. A Social Class Index, based on respondent's current occupation and highest level of education, was not shown to significantly constrain accent evaluations in any of our models, whether independently or in combination with age. Conforming to standard language norms in judgments of professionalsounding speech therefore appears to be a general property of later life stages, rather than an artefact of older individuals generally being of a higher social class. ${ }^{5}$ Overall, our analyses thus contribute further evidence of a persistent hierarchy of accent prestige in professional contexts in England, albeit one that only appears to affect evaluative judgments later in life. Given that $61 \%$ of professional managers and directors in England are over the age of 40 (Office of National Statistics 2011), there is a good chance that this accent hierarchy could continue to disadvantage speakers of Southern ethnic and non-standard varieties (EE and MLE) attempting to access employment in an elite profession. 


\subsection{Regional Skew in the Prevalence of Bias}

The effect of age on accent evaluations in professional contexts is further conditioned by complex higher-order interactions with other listener characteristics. These additional effects serve to demonstrate the very nuanced nature of current attitudes to what constitutes professional-sounding speech in England. The first of these, listener region, is illustrated in Figure 3. For ease of presentation, age is depicted in Figure 3 as a binary category, split between "older" respondents (those over the median age of 47) and "younger" respondents (those below it). In addition, accent evaluations are partitioned in Figure 3 according to whether respondents currently reside in the North of England, the South of England or the Midlands. We see that, overall, mean evaluations are lower among older respondents than they are among younger respondents, replicating the general downward slopes of the trend lines in Figure 2. In fact, Figure 3 shows that that it is only among older respondents in the South, and to a lesser extent the Midlands, that we find a downgrading of EE and MLE as compared to RP, GNE or UWYE. For older respondents in the North, as for all younger respondents, we see no apparent differences in ratings across accents.

Figure 3: Accent Evaluations by Age and Region (Model Predicted Values) [FIGURE 3 HERE]

\subsection{Factors Mitigating Bias: Expert Knowledge}

The relationship between age, region and accent evaluation is in fact complicated by interactions with two further factors that mitigate the potentially discriminatory effects of accent bias in a legal context. The first involves the type of question speakers are responding to. Recall that half of the questions in the survey required specific knowledge of the law, testing the (mock) candidates' legal expertise. These "expert" questions were paired with a 
set of "non-expert" questions that probed candidates" generic professional skills more broadly. Analyses demonstrate that the interaction of age, region and question type (expert vs. non-expert) has a significant impact on mean evaluations across accents $(F(8,6235.6)=$ 2.88, $\mathrm{p}=0.003$ ). This effect is illustrated in Figure 4. We see that, across the board, responses to questions requiring legal expertise receive higher mean ratings than responses to questions about generic professional skills. This kind of expertise "boost" is predicted by social psychological frameworks of competence assessment, which model the relationship between so-called status characteristics and inferred performance expectations (Berger, Fisek, Norman \& Zelditch 1977; Berger, Rosenholtz \& Zelditch 1980; Foschi 2000; Simpson \& Walker 2002). According to these models, listeners attend to various cues when making inferences about speaker ability. Prominent among these are cues to specific status characteristics, such as knowledge or expertise in a relevant domain (e.g., law). Such models therefore predict that responses to interview questions requiring expert knowledge will result in judgments of higher levels of competence.

Figure 4: Accent Evaluations by Age, Region and Question Type (Model Predicted Values). Boxes and asterisks indicate a significant difference between RP and a given accent in that condition.

[FIGURE 4 HERE]

Yet in addition to the over-arching effect of expertise, Figure 4 also illustrates that not all respondents apply the expertise boost in the same way across accents. This indicates that while expert content may mitigate accent-linked effects, it does not fully override them. (Note too that mean ratings of even the expert questions never exceed 7.5 out of 10 , demonstrating that the expertise boost does not lead to ceiling effects among respondents.) To 
identify significant contrasts in the complex interaction illustrated in Figure 4, post-hoc tests (using the emmeans package in R; Lenth 2020) compare mean evaluations of GNE, UWYE, $\mathrm{EE}$ and MLE to mean evaluations of RP, given that RP consistently receives top ratings. Post-hoc tests therefore determine whether respondents significantly downgrade the perceived hirability of speakers of other accents, as compared to speakers of RP. The results of these tests show two relevant effects. The first relates to a narrow effect of expert content on older Midlands listeners' evaluation of MLE, and the second to a broader effect among older Southern listeners.

When older listeners in the Midlands (the right panel in the middle row of Figure 4) evaluate non-expert questions, they rate candidates who speak with an MLE accent significantly lower than candidates with an RP accent. This difference among older listeners in the Midlands only obtains for non-expert questions, with no significant differences attested across accents when they rate responses to expert questions. The presence of an accent effect in older Midlands listeners' evaluations of non-expert questions and its absence in their evaluations of expert questions illustrate a further component of status characteristics theory, first introduced above. While an attribute like legal expertise is a specific status characteristic that cues specific performance expectations, the theory also recognizes what are termed diffuse status characteristics, such as class or ethnicity, that cue general behavioral or performance expectations. The difference between the two is the range of applicability of the performance expectations that a characteristic generates: specific characteristics are associated with performance expectations in a restricted domain whereas diffuse characteristics also link to "expectations about performance on a wide, indeterminate set of tasks" (Foschi 2000:23). Prior research has demonstrated that various social categories (like age, gender, race and socioeconomic status) function as diffuse characteristics, underlying the formation of expectations about both general states (e.g., intelligence, empathy) and specific 
abilities (e.g., spatial reasoning, mathematical processing) (e.g., Freese \& Cohen 1973; Webster \& Driskell 1978; Wagner, Ford \& Ford 1986). For older respondents in the Midlands, it appears that MLE functions as a cue to a diffuse characteristic (ethnicity and/or social class), which in turns leads to a lower level of inferred competence, and hence hirability, of MLE speakers. That MLE only has this effect for non-expert questions reflects the contention that specific status cues tend to take precedence over diffuse ones (Hembroff \& Myers 1984; Dovidio, Brown, Heltman, Ellyson \& Keating 1988), such that expert content (a cue to the specific status characteristic of knowledge/expertise) renders accent (a diffuse cue to ethnicity and/or social class) irrelevant to the task at hand.

The second significant effect identified in post-hoc testing is that older Southern listeners (the right panel in the top row of Figure 4) also evaluate MLE speakers as significantly less hirable than RP speakers, like older Midlands listeners. However, they do so for both expert and non-expert questions, and for candidates with both MLE and EE accents. In other words, older listeners in the South significantly downgrade speakers of both Southern non-standard varieties (EE and MLE) irrespective of whether the question requires the candidate to demonstrate expert knowledge or not. This is not to say that the expert/nonexpert distinction has no effect on older Southern respondents. Across all accents (including EE and MLE), older Southerners rate responses to expert questions significantly higher than responses to non-expert questions. But in both cases, they also rate EE and MLE speakers as significantly less hirable than RP speakers. This result illustrates that the precedence of specific characteristics over diffuse characteristics in cueing performance expectations is not absolute (Berger, Fisek, Norman \& Zelditch 1977; Simpson \& Walker 2002). At least for older Southern listeners, we see that diffuse characteristics of race and class establish competence-related expectations even in the presence of specific cues to expert legal knowledge. 
Taken together, the results illustrated in Figure 4 indicate that while there exists an overall effect whereby older respondents rate speakers of EE and MLE as significantly less hirable than speakers of other accents, that effect is primarily driven by respondents in the South and the Midlands and exists in a complex interaction with the type of question that is asked. We have argued that the question type effects can be accounted for via recourse to models of competence assessment, and specifically the performance expectations that listeners generate based on cues to specific and diffuse status characteristics of speakers.

The issue we have yet to address is why we only find attention to accent - and specifically to EE and MLE - as a diffuse status characteristic among listeners in the South and the Midlands. Based on the data gathered for the current study, we can only provide tentative initial responses to this question. It could be the case that listeners in the South and the Midlands are more sensitive to non-standard Southern varieties than listeners in the North as a result of the well-documented out-group homogeneity effect (Judd \& Park 1988; Judd, Ryan \& Park 1991), whereby greater degrees of in-group variability are observed for in-group distinctions than for out-group ones. In other words, people tend to make finer distinctions about patterns of behavior that are perceived as "local" than those that are perceived as "external". This could be why, for instance, we find reactions to both EE and MLE among Southern listeners, given that both are (and are perceived as) Southern accents. The significant effect of MLE among listeners in the Midlands could then be due to the fact that multiethnic varieties have also emerged in other major British urban centers, including Birmingham (e.g., Khan 2006). This interpretation remains speculative, and could be tested in future work in relation to new multiethnic accents in the North (e.g., Drummond 2017; Stuart-Smith, Timmins \& Alam 2011). We also note that the increased sensitivity of Southern and Midlands listeners to EE and MLE could be due to greater exposure of these listeners to these varieties (a pattern that some scholars have argued is what underlies the out-group homogeneity effect to begin with; e.g., 
Linville \& Fischer 1993). Once again, a close examination of familiarity effects (e.g., Adank, Evans, Stuart-Smith \& Scott 2009) in our data is beyond the scope of the current study. For the moment, we note simply that region asserts a constraining influence on the competence assessment process, and leave a fuller explanation of region as a social constraint for future research.

Nevertheless, it is important to point out that an account based solely on in-group membership or solidarity would not capture the range of findings observed. An in-/out-groupbased account, for example, might lead us to expect differences in how Northern listeners evaluate GNE as compared to RP, but such a difference is not attested (see Figure 4). Similarly, we see no downgrading of RP among any of the listener groups, despite RP being an out-group variety for many (though potentially highly familiar to all). Thus, while in-group/out-group distinctions may certainly play a role in listeners' rankings, they do not provide the whole story. Crucially, we would add that the group demonstrating the greatest amount of bias in a professional context is older Southern listeners, i.e., the group that is proportionally overrepresented in elite professions in the UK. Hence, even if older Southern listeners' attitudes are ultimately reducible to an out-group effect, the fact remains that it is this group of listeners that currently has the most influence over professional outcomes in elite employment sectors and that simultaneously displays the clearest gate-keeping attitudes in terms of language.

\subsection{Factors Mitigating Bias: Motivation to Control a Prejudiced Response}

Further information about variability in accent perceptions across listeners is provided by one additional significant interaction in the data. Classic sociolinguistic matched-guise studies tend to focus on demographic traits of respondents more than psychological states, but we hypothesized that a respondent's personal motivation to control or hide prejudiced reactions (MCPR; Dunton \& Fazio 1997) could be very relevant. MCPR is an individual difference 
measure that reflects a respondent's desire to appear nonprejudiced to others and/or a distaste for prejudicial behavior. Crucially, MCPR is independent of actually maintaining prejudiced beliefs, and instead refers to an individual's motivation to engage in more deliberative, as opposed to more automatic, processing as a way of avoiding potentially prejudiced reactions. MCPR is measured by a multi-item self-report questionnaire. We included an adapted 5-item version of the questionnaire in our survey. Figure 5 illustrates the results of our analysis of MCPR on accent ratings.

Figure 5: Accent Evaluations by Age, Region and Motivation to Control Prejudiced Response (Model Predicted Values). Boxes and asterisks indicate a significant difference between RP and a given accent in that condition.

[FIGURE 5 HERE]

MCPR has a robust effect on listener evaluations across the dataset $(\mathrm{F}(1,826.7)=$ 90.199, $\mathrm{p}<0.001)$ : respondents with higher levels of MCPR give candidates significantly higher ratings than respondents with lower levels do. This effect, moreover, extends across accents. We see no significant differences in ratings of accents among listeners with high MCPR. Instead, the only accent effects we find are among the same respondents identified above (i.e., older listeners in the South and the Midlands), and there only for respondents with low levels of MCPR. Among this group of listeners (older listeners in the South and the Midlands with low levels of MCPR), ratings parallel those observed in Figure 4, with MLE and, to a lesser extent, EE speakers judged as significantly less hirable than speakers of RP. Findings with respect to MCPR thus provide further support for our claim that it is Southern non-standard varieties (i.e., EE and MLE) that lead to decreased perceptions of a candidates' hirability and, as a result, evidence of bias against speakers of these two accents in professional 
contexts. However, this pattern of bias only appears to operate with a subset of the respondent population - older listeners in the South and the Midlands - and even there is mitigated by both expert content (seen in Figure 4) and a respondent's motivation to control a prejudiced response (seen in Figure 5).

\subsection{Summary}

Table 5 presents an overview of the findings of our survey of attitudes to five English accents. Consistent with previous research on language attitudes in Britain, we find evidence of an enduring hierarchy of accent prestige that serves to privilege certain accents over others. However, we also find that accent attitudes are more nuanced than has been previously reported and that the hierarchy of accent prestige is constrained by a number of social, contextual and psychological factors. At the broadest level of generality, accent attitudes are influenced by age, such that older respondents (i.e., over the age of 45) judge speakers of the two standard working-class accents (EE and MLE) to be significantly less "hirable" than are speakers of RP or either of the Northern accents. We interpret this pattern as being related to the different life stages of the respondents, and specifically to an increased socialization in, and enhanced orientation to, traditional workplace norms among older listeners (Eckert 1997). Results also demonstrate, however, that this age effect does not operate identically across regions of England. Respondents in the north of the country show no apparent evaluative differences across accents, while (older) respondents in the Midlands and the South do. We suggest that these regional differences may be linked to differential treatment of perceived in-group versus out-group accents (Judd and Park 1988) and/or varying levels of exposure to the accents in question, though we maintain that in-group/outgroup effects are unable to provide the full story. Nevertheless, our results clearly 
demonstrate that attitudes to accent variation in England are moderated by both respondent age and region.

\section{Table 5}

Summary of Significant Constraints on Accent Evaluations in England

[TABLE 5 HERE]

In addition to the moderating factors of age and region, analyses indicate that bias against Southern working-class accents is mitigated by stimulus content and by respondents' own psychological predispositions. In terms of content, providing a response to an interview question that requires legal expertise correlates with a boost in evaluative ratings. This effect applies across the board, though older Southern listeners still judge EE- and MLE-speaking candidates as less "hirable" than speakers of other varieties even when these candidates are answering expert questions, indicating the persistence of bias for these listeners. We interpret these patterns in relation to well-known theories of competence assessment (e.g., Berger, Fisek, Norman \& Zelditch 1977), arguing that expert content and accent both function as cues to status characteristics, though they differ in whether those cues are specific (expert content) or diffuse (accent). Finally, we find a robust effect of individual motivation to control a prejudiced response (Dunton \& Fazio 1997), in which people who are more highly motivated not to appear prejudiced to others evaluate candidates more favorably. This individual difference is strong enough to trump any accent bias effects, such that differences in evaluation across accents only appear for respondents with lower levels of MCPR. While we remain agnostic as to whether this MCPR effect is a function of increased deliberative processing or an explicit strategy for avoiding the appearance of bias, we note that the 
powerful effect of this psychological factor argues for incorporating it more systematically into research on language attitudes.

Taken together, our results demonstrate that members of the general public in England perceive certain accents as being a "mismatch" for a job as a lawyer. This result is in line with popular and anecdotal discussions of accents in the UK (e.g., Baratta, 2017, 2018), and demonstrates the persistence of accent bias in British society. Yet at the same time, our results suggest that this bias may be more nuanced than previously reported. As we note in our review of the previous literature, there have been few recent studies of accent attitudes in the UK using audio speech samples (as opposed to labels for accent concepts), and what studies have appeared have tended not to situate their investigations within specific social and/or professional contexts. We contend that such contextual embedding is crucial for the robust identification of attitudes to accents and for describing the language ideological landscape of England more generally, since, as much prior research has shown, attitudes are highly sensitive to the specific conditions in which they are elicited (e.g., Preston 2010).

Further support for the importance of context in structuring attitudinal responses appears in other studies conducted as part of the Accent Bias in Britain project. Though a full discussion of these other experiments is beyond the scope of the current article, we briefly highlight results of two of these studies. In a direct replication of Coupland and Bishop's examination of attitudes to accent labels (Bishop, Coupland, and Garrett 2005; Coupland and Bishop 2007), we asked a large, nationally representative sample of the UK public to rate labels of 38 different accents of English for their perceived prestige (Sharma, Levon \& Ye, in press). Our findings largely replicate those of Coupland and Bishop from 15 years ago, demonstrating pervasive bias against labels for certain non-standard accents, bias that far exceeds the evaluative differences we identify in the present article when considering listener reactions to speech samples in a situated social context. 
Conversely, we also conducted an experiment similar to the one discussed in the present article, where listeners rated audio speech samples from mock legal interviews, but where the listener population comprised a group of lawyers and other legal professionals who completed the experiment in their workplace (Levon, Sharma, Ye, Cardoso \& Watt 2021). In that experiment, we also included an additional quality manipulation to further reduce demand characteristics, whereby participants in an experiment become aware of the purpose of the study (e.g., McCambridge, de Bruin \& Witton 2012). We implemented a quality manipulation by presenting respondents with interview responses in all accents that varied between marginally better or worse in quality, based on pre-testing in written form with an independent group of lawyers. In this workplace study, we found no evidence of accent bias whatsoever. Rather, analyses revealed that listeners with training and recruiting experience in the legal profession were able to judge candidates objectively and without letting a candidate's accent influence their evaluations. Importantly, we do not interpret this result as indicating that lawyers have no bias. Rather, we suggest that the context of the study, which required respondents to focus on the quality of interview responses and which was conducted in the workplace, enabled legal professionals to focus on specific status characteristics (response quality) and to ignore diffuse ones (accent). This argument is supported by a comparison of legal professionals' ratings in the workplace study with those of legal and other professional respondents in the wider nationwide study. In the latter case, professional respondents (corresponding to occupational class categories 1 and 2 of the UK Office for National Statistics classification system) behaved precisely like the rest of the respondent population, showing bias against speakers of Southern working-class varieties. Only when we surveyed lawyers in the workplace and with an additional quality manipulation to attend to do we find no effects of accent bias (for a further discussion of the results of the workplace study, see Levon, Sharma, Ye, Cardoso \& Watt 2021). 
A comparison of results across these three studies leads us to conclude that context and task-specific goals are the primary drivers of accent bias effects. In the labels study, participants reported their general attitudes to accent divorced from any specific situational context. In the present nationwide study, members of the public compared social group stereotypes (signaled by accent) with a specific role stereotype (lawyer). Finally, in the workplace study, expert respondents evaluated the specific quality of candidate responses in a context (their workplace) where such evaluations are common. The incremental decrease in the scope of accent bias effects we observe across these three studies is thus concomitant with a parallel increase in the amount of contextual enrichment and goal-directed behavior involved. We suggest that an increase in contextual enrichment correlates with a corresponding reliance on specific status characteristics to the exclusion of diffuse ones, like accent. Thus, while the findings of the current study may have revealed more nuanced effects of accent bias than in prior work, we argue that this discrepancy results from our examination of attitudes within a specific professional context and from the ways in which context interacts with attitude formation more generally (see, e.g., Cargile, Giles, Ryan \& Bradac 1994; Gawronski, Ye, Rydell \& De Houwer 2014; Hilton \& Jeong 2019; Levon \& Ye 2020).

\section{Conclusion}

The epigram by George Bernard Shaw with which we began this article is a testament to the long-standing association in Britain between language and social position. While British society has changed in myriad ways since Shaw's time, our research demonstrates that popular beliefs continue to treat accent as a signal of an individual's competence and capability. While we acknowledge that our results are drawn from the general public as opposed to an actual hiring context, we nevertheless argue that they are important in demonstrating the potential for accent bias to interfere with objective assessments of 
professional competence. Our findings clearly indicate that a perceived mismatch between speakers of certain accents and a job as a lawyer is part of the cultural context of British society, a context in which legal professionals are themselves socialized. And while our research on this topic shows that such bias can be mitigated and even overcome (by, for example, expert content, respondent MCPR and specific eliciting conditions) the fact remains that a predisposition to accent bias exists, a predisposition that we believe may play a larger role in impeding social mobility in the UK than has been recognized to date. Even though much research has documented the ways in which social inequalities in Britain are perpetuated and maintained (e.g., Clark 2014; Ashley, Duberley, Sommerland \& Scholarios 2015; Friedman, Laurison \& Miles 2015), accent - as a powerful, though subtle, marker of social background and perceived "polish" - has tended to fly below the radar. Ultimately, we hope through this study to have demonstrated the importance of taking accent and the potential for accent bias into account in studies of social mobility.

That said, we also note that the analyses presented in the current article only scratch the surface with respect to the different ways in which language may affect life outcomes. As noted above, other projects of the Accent Bias in Britain initiative examine evaluations of accents by professionals in elite law firms (e.g., lawyers and professional recruiters) and compare how listeners evaluate audio stimuli versus simple accent labels, in order to develop a fuller understanding of the role of context and past experience in influencing attitude formation. We are also working to identify the specific linguistic elements that cue attitudinal responses, examining whether evaluative reactions are driven by specific accent "shibboleths" or by more cumulative, holistic perceptions, and to investigate evaluative trajectories in real-time. Through this, we hope to develop a better understanding of what it means to have an attitude to an accent, and to model the underlying sociolinguistic processing that gives rise to evaluative reactions. Finally, we are also testing different strategies for 
combating accent bias, with a view to determining whether anti-bias interventions that have been developed for other forms of discrimination can be applied to accent as well. The resulting evidence-based recommendations are being embedded in professional recruiter training and national HR guidelines.

The unifying goal of the larger project is thus to provide a nuanced account of contemporary attitudes to accent variation in the UK within a particular social context, a consideration of how those attitudes may act as impediments to professional advancement, and a way out of a vicious circle of invisibility and marginalization of under-represented candidates (Darity \& Mason 1998). We recognize that our work is by necessity very constrained, focusing on a restricted range of accents, a single professional context (law), and a specific point in the professional lifecycle (entry-level recruitment). Nevertheless, it is our hope that results like those presented in this article serve to highlight the role that accent and accent bias may play in perpetuating social inequalities, and to encourage further research on language and social mobility in professional contexts and in a wider range of social and linguistic situations. This further work is crucial to mapping the real effects that accent bias may have on professional outcomes and in helping to ensure that when language-related biases do exist, they can no longer pass below the radar.

\section{Notes}

1 Pitch manipulations were minimal, and involved shifts of no more than $5-10 \mathrm{~Hz}$ for certain speakers.

2 A Latin Square is a type of partial factorial experimental design that allows for the distribution of stimuli representing a number of experimental parameters (in our case, accents, speakers and questions) across respondents without repeating a particular combination of parameters for any one respondent. 
3 Initial inspections of data distributions reveal no apparent differences in accent evaluations as a function of respondent gender or beliefs about the existence of regional or social class bias. As a result, we do not consider these factors in our analyses.

Preliminary inspections also reveal no immediately apparent differences as a function of respondent linguistic background (repertoire, own accent, mobility), though we concede that further research beyond the scope of the current analysis is required to fully investigate these dimensions.

4 Coupland \& Bishop (2007) do not consider Estuary English in their study, preferring instead the more positively connoted label London English.

5 Analyses that included respondent occupation on its own, rather than as part of a Social Class Index that also included level of education, likewise showed no significant effects in our models.

\section{Appendix}

Analysis of Variance Table for Best Model (Type III)

\begin{tabular}{lcccccc}
\hline \hline Fixed Effects & Sum Sq & df & $\boldsymbol{F}$ & $\boldsymbol{p}$-value & \\
\hline Accent & 2.166 & 4 & 0.359 & 0.829 & \\
QuesType & 4.951 & 1 & 3.278 & 0.107 & \\
MCPR & $\mathbf{1 3 6 . 2 5 0}$ & $\mathbf{1}$ & $\mathbf{9 0 . 1 9 9}$ & $\mathbf{0 . 0 0 0}$ & $* * *$ \\
Region & 4.009 & 2 & 1.327 & 0.266 & \\
Age & $\mathbf{3 5 . 9 2 6}$ & $\mathbf{1}$ & $\mathbf{2 3 . 7 8 3}$ & $\mathbf{0 . 0 0 0}$ & $* * *$ \\
Accent:QuesType & 3.101 & 4 & 0.513 & 0.726 & \\
Accent:MCPR & 5.799 & 4 & 0.960 & 0.428 & \\
QuesType:MCPR & 1.826 & 1 & 1.209 & 0.272 & \\
Accent:Region & 5.491 & 8 & 0.454 & 0.888 & \\
QuesType:Region & 1.800 & 2 & 0.596 & 0.551 & \\
MCPR:Region & 0.010 & 2 & 0.003 & 0.997 & \\
Accent:Age & $\mathbf{2 9 . 6 1 1}$ & $\mathbf{4}$ & $\mathbf{4 . 9 0 1}$ & $\mathbf{0 . 0 0 1}$ & $* * *$ \\
QuesType:Age & $\mathbf{9 . 0 1 8}$ & $\mathbf{1}$ & $\mathbf{5 . 9 7 0}$ & $\mathbf{0 . 0 1 5}$ & $* * *$ \\
MCPR:Age & 0.051 & 1 & 0.034 & 0.854 & \\
Region:Age & 7.891 & 2 & 2.612 & 0.074 & \\
Accent:QuesType:MCPR & 12.291 & 4 & 2.034 & 0.087 & \\
Accent:QuesType:Region & 8.577 & 8 & 0.710 & 0.683 &
\end{tabular}




\begin{tabular}{lccccc} 
Accent:MCPR:Region & 6.052 & 8 & 0.501 & 0.856 & \\
QuesType:MCPR:Region & 2.190 & 2 & 0.725 & 0.485 & \\
Accent:QuesType:Age & 3.641 & 4 & 0.603 & 0.661 & \\
Accent:MCPR:Age & 7.778 & 4 & 1.287 & 0.273 & \\
QuesType:MCPR:Age & 4.359 & 1 & 2.885 & 0.090 & \\
Accent:Region:Age & 7.741 & 8 & 0.641 & 0.744 & \\
QuesType:Region:Age & 1.697 & 2 & 0.562 & 0.570 & \\
MCPR:Region:Age & 2.895 & 2 & 0.958 & 0.384 & \\
Accent:QuesType:MCPR:Region & 6.909 & 8 & 0.572 & 0.802 & \\
Accent:QuesType:MCPR:Age & 6.802 & 4 & 1.126 & 0.342 & \\
Accent:QuesType:Region:Age & $\mathbf{3 4 . 7 6 0}$ & $\mathbf{8}$ & $\mathbf{2 . 8 7 6}$ & $\mathbf{0 . 0 0 3}$ & $* * *$ \\
Accent:MCPR:Region:Age & $\mathbf{3 3 . 1 4 5}$ & $\mathbf{8}$ & $\mathbf{2 . 7 4 3}$ & $\mathbf{0 . 0 0 5}$ & $* * *$ \\
QuesType:MCPR:Region:Age & 1.887 & 2 & 0.625 & 0.536 & \\
\hline \hline
\end{tabular}

Total observations: 8480

Random intercepts: Respondent (848), Speaker (10), Question (10), Speaker:Question (100)

Random slopes: Respondent : Accent (4230), Respondent : QuestType (1692)

Log likelihood $=-16126.4$, Conditional $\mathrm{R}^{2}=0.596$

\section{References}

Adank, Patti, Bronwen Evans, Jane Stuart-Smith \& Sophie Scott. 2009. Comprehension of familiar and unfamiliar native accents under adverse listening conditions. Journal of Experimental Psychology: Human Perception and Performance 35(2). 520-529.

Ajzen, Icek. 1991. The Theory of Planned Behavior. Organizational Behavior and Human Decision Processes 50(2). 179-211.

Ajzen, Icek. 2005. Attitudes, personality and behavior. Maidenhead: Open University Press. Alemoru, Kemi. 2015. "You don't sound like them": A sociolinguistic investigation into how race interacts with the perception and attitude towards Multicultural London English. Sheffield: University of Sheffield MA dissertation.

Altendorf, Ulrike. 2003. Estuary English: Levelling at the interface of RP and South-Eastern British English. Tübingen: Gunter Narr.

Ashley, Louise, Jo Duberley, Hilary Sommerlad \& Dora Scholarios. 2015. A qualitative evaluation of non-educational barriers to the elite professions. London: Social Mobility Commission. 
Badia Barrera, Berta. 2016. A sociolinguistic study of /t/ glottalling in young RP: Accent, class and education'. Colchester: University of Essex PhD thesis.

Baratta, Alex. 2017. Accent and linguistic prejudice within British teacher training. Journal of Language, Identity and Education 16(6). 416-423.

Baratta, Alex. 2018. Accent and teacher identity in Britain: Linguistic favouritism and imposed identities. London: Bloomsbury.

Bates, Douglas, Martin Mächler, Ben Bolker \& Steve Walker. 2015. Fitting linear mixedeffects models using lme4. Journal of Statistical Software 67(1). 1-48.

Baxter, Holly. 2016. May and social mobility: Actions speak louder than words. The Independent. 13 July.

Beal, Joan. 2004. The phonology of English dialects in the north of England'. In Bernd Kortmann \& Edgar Schneider (eds.) A handbook of varieties of English, vol. 1, 113-133. Berlin: de Gruyter.

Beal, Joan. 2009. Enregisterment, commodification and historical context: "Geordie" versus "Sheffieldish". American Speech 84(2). 138-156.

Berger, Joseph, M. Hamit Fisek, Robert Norman \& Morris Zelditch. 1977. Status characteristics and social interaction: An expectation states approach. New York: Elsevier.

Berger, Joseph, Susan J. Rosenholtz \& Morris Zelditch. 1980. Status Organizing Processes. Annual Review of Sociology 6(1). 479-508.

Bishop, Hywel, Nikolas Coupland \& Peter Garrett. 2005. Conceptual accent evaluation: Thirty years of accent prejudice in the UK'. Acta Linguistica Hafniensia 37(1). 131-154.

Blanden, Jo, Alissa Goodman, Paul Gregg \& Stephen Machin. 2004. Changes in intergenerational mobility in Britain'. In Miles Corak (ed.) Generational income mobility in North America and Europe, 122-146. Cambridge: Cambridge University Press. 
Blanden, Jo, Paul Gregg \& Stephen Machin. 2005. Educational inequality and intergenerational mobility'. In Stephen Machin \& Anna Vignoles (eds.) What's the good of education? The economics of education in the UK, 99-114. Princeton: Princeton University Press.

Buscha, Franz \& Patrick Sturgis. 2018. Declining social mobility? Evidence from five linked censuses in England and Wales 1971-2011. The British Journal of Sociology 69(1): 154182.

Cabinet Office. 2011. Opening doors, breaking barriers: A strategy for social mobility. https://assets.publishing.service.gov.uk/government/uploads/system/uploads/attachment_d ata/file/61964/opening-doors-breaking-barriers.pdf.

Campbell-Kibler, Kathryn. 2009. The nature of sociolinguistic perception. Language Variation and Change 21(1). 135-156.

Cargile, Aaron, Howard Giles, Helen Ryan \& James Bradac. 1994. Language attitudes as a social process: A conceptual model and new directions. Language and Communication 14 (3). 211-236.

Chaiken, Shelly \& Durairaj Maheswaran. 1994. Heuristic processing can bias systematic processing: Effects of source credibility, argument ambiguity, and task importance on attitude judgment. Journal of Personality and Social Psychology 66(3). 460-473.

Chartered Institute of Personnel and Development. 2006. Diversity in business: How much progress have employers made? https://www.cipd.co.uk/NR/rdonlyres/53CF3D4F-22154DA6-AEBF-C67C99A67F1C/0/diversbus0606.pdf.

Cheshire, Jenny, Susan Fox, Paul Kerswill \& Eivind Torgersen. 2008. Ethnicity, friendship network, and social practices as the motor of dialect change: Linguistic innovation in London'. Sociolinguistica 22(1). 1-23. 
Cheshire, Jenny, Paul Kerswill, Sue Fox \& Eivind Torgersen. 2011. Contact, the feature pool, and the speech community: The emergence of Multicultural London English'. Journal of Sociolinguistics 15(2). 151-196.

Clark, Gregory. 2014. The son also rises: Surnames and the history of social mobility. Princeton: Princeton University Press.

Clark, Gregory \& Neil Cummins. 2013. Surnames and social mobility: England 1230-2012. LSE Economic History Working Papers 181.

Coates, Sam. 2016. Carry on Cameron - For another four years. The Times. 1 January. Collins, Beverly \& Inger Mees. 1999. The real Professor Higgins: The life and career of Daniel Jones. Berlin: Walter de Gruyter.

Cooper, Robert. 1975. Introduction to language attitudes. International Journal of the Sociology of Language 6. 5-9.

Cooper, Robert \& Joshua Fishman. 1974. The study of language attitudes. International Journal of the Sociology of Language 3. 5-20.

Coupland, Nikolas \& Hywel Bishop. 2007. Ideologized values for British Accents. Journal of Sociolinguistics 11(1). 74-93.

Darity, William \& Patrick Mason. 1998. Evidence on discrimination in employment: Codes of color, codes of gender. Journal of Economic Perspectives 12(2). 63-90.

Devine, Fiona \& Helene Snee. 2015. Doing the Great British Class Survey. The Sociological Review 63(2). 240-258.

Dixon, John, Berenice Mahoney \& Roger Cocks. 2002. Accents of G=guilt? Effects of regional accent, race and crime type on attributions of guilt. Journal of Language and Social Psychology 21(2). 162-168. 
Dovidio, John, Clifford Brown, Karen Heltman, Steve Ellyson \& Caroline Keating. 1988. Power displays between women and men in discussions of gender-linked tasks: A multichannel study. Journal of Personality and Social Psychology 55(4). 580-587.

Drummond, Rob. 2017. (Mis)interpreting urban youth language: White kids sounding Black?' Journal of Youth Studies 20(5) 640-660.

Dunton, Bridget \& Russell Fazio. 1997. An individual difference measure of motivation to control prejudiced reactions. Personality and Social Psychology Bulletin 23(3): 316-326.

Eagly, Alice \& Amanda Diekman. 2005. What is the problem? Prejudice as an attitude-incontext. In John Dovidio, Peter Glick \& Laurie Rudman (eds.) On the nature of prejudice: Fifty years after Allport, 19-35. Malden: Blackwell.

Eckert, Penelope. 1997. Age as a sociolinguistic variable'. In Florian Coulmas (ed.) The handbook of sociolinguistics, 151-167. Oxford: Wiley-Blackwell.

Ellis, Alexander. 1869. On Early English pronunciation, vol. 1. London: Truebner and Co.

Fabricius, Anne. 2000. t-glottalling: Between stigma and prestige: A sociolinguistic study of modern RP'. Copenhagen: Copenhagen Business School PhD thesis.

Fabricius, Anne. 2005. Mobility, contact and an accent norm: The case of Received Pronunciation'. In Bent Preisler, Anne Fabricius, Hartmut Haberland, Susanne Kjaerbeck \& Karen Risager (eds.) The Consequences of Mobility, 120-134. Roskilde: Roskilde University.

Fabricius, Anne. 2006. The ‘vivid sociolinguistic profiling' of Received Pronunciation: Responses to gendered dialect in discourse'. Journal of Sociolinguistics 10(1). 111-122. Foschi, Martha. 2000. Double standards for competence: Theory and research'. Annual Review of Sociology 26(1). 21-42.

Fox, Kate. 2004. Watching the English: The hidden rules of English Behaviour. London: Arnold. 
Freese, Lee \& Bernard Cohen. 1973. Eliminating status generalization'. Sociometry 36(2). $177-193$.

Friedman, Sam, Daniel Laurison \& Andrew Miles. 2015. Breaking the "class" ceiling? Social mobility into Britain's elite occupations. The Sociological Review 63(2). 259-289.

Fry, Stephen. 2011. Fry’s English delight series 4: Class. BBC Radio 4.

Garrett, Peter, Nikolas Coupland \& Angie Williams. 1999. Evaluating dialect in discourse: Teachers' and teenagers' responses to young English speakers in Wales'. Language in Society 28(3). 321-354.

Gawronski, Bertram, Yang Ye, Robert Rydell \& Jan De Houwer. 2014. Formation, representation and activation of contextualized attitudes. Journal of Experimental Social Psychology 54. 188-203.

Giles, Howard. 1970. Evaluative reactions to accents. Educational Review 22(3). 211-227.

Giles, Howard. 1973. Accent mobility: A model and some data. Anthropological Linguistics 15(2). 87-105.

Giles, Howard, Susan Baker \& Guy Fielding. 1975. Communication length as a behavioural index of accent prejudice. International Journal of the Sociology of Language 6. 73-82.

Giles, Howard, Richard Bourhis, Peter Trudgill \& Alan Lewis. 1974. The Imposed Norm Hypothesis: A validation. The Quarterly Journal of Speech 60(4). 405-410.

Giles, Howard, Pamela Wilson \& Anthony Conway. 1981. Accents and lexical diversity as determinants of impression formation and perceived employment suitability. Language Sciences 3(1). 91-103.

Grondelaers, Stefan, Roeland van Hout \& Paul van Gent. 2018. Re-evaluating the prestige of regional accents in Netherlandic Standard Dutch: The role of accent strength and speaker gender. Journal of Language and Social Psychology 38(2) 215-236. 
Heath, Anthony \& Sin Yi Cheung. 2006. Ethnic penalties in the labour market: Employers and discrimination. UK Department for Work and Pension Research Report 341.

Hembroff, Larry \& David Myers. 1984. Status characteristics: Degrees of task relevance and decision processes. Social Psychology Quarterly 47(4). 337-346.

Hewlett, Nigel \& Monica Rendall. 1998. Rural versus urban accent as an influence on the rate of speech. Journal of the International Phonetic Association 28(1-2). 63-71.

Hilton, Katherine \& Sunwoo Jeong. 2019. The role of context in sociolinguistic perception. Linguistics Vanguard 5(s1): 20180069.

Hiraga, Yuko. 2005. British attitudes towards six varieties of English in the USA and Britain'. World Englishes 24(3). 289-308.

Jacewicz, Ewa, Robert Fox \& Joseph Salmons. 2007. Vowel duration in three American English dialects. American Speech 82(4). 367-385.

Jones, Daniel. 1937. On "Received Pronunciation”. Supplement to Le Maitre Phonetique 3 (15). $1-2$.

Judd, Charles \& Bernadette Park. 1988. Out-group homogeneity: Judgments of variability at the individual and group levels. Journal of Personality and Social Psychology 54 (5) 778 788.

Judd, Charles, Carey Ryan \& Bernadette Park. 1991. Accuracy in the judgment of in-group and out-group variability'. Journal of Personality and Social Psychology 61 (3). 366-379.

Kalin, Robert, Donald Rayko \& Nathan Love. 1980. The perception and evaluation of job candidates with four different ethnic accents. In Howard Giles, W. Peter Robertson \& Philip Smith (eds.) Language: Social Psychological Perspectives, 197-202. Oxford: Pergamon.

Khan, Arfaan. 2006. A sociolinguistic study of Birmingham English: Language variation and change in a multi-ethnic British community'. Lancaster: Lancaster University $\mathrm{PhD}$ thesis. 
Kircher, Ruth \& Susan Fox. 2019. Multicultural London English and its Speakers: A corpusinformed discourse study of standard language ideology and social stereotypes. Journal of Multilingual and Multicultural Development.

Kraus, Michael W., Brittany Torrez, Jun Won Park \& Fariba Ghayebi. 2019. Evidence for the reproduction of social class in brief speech. Proceedings of the National Academy of Sciences, 201900500.

Kuznetsova, Alexandra, Per B. Brockhoff \& Rune H. B. Christensen. 2017. lmerTest package: Tests in linear mixed effects models. Journal of Statistical Software 82(1). 1-26.

Labov, William. 2001. Principles of linguistic change: Social factors. Oxford: Blackwell.

Lenth, Russell. 2020. emmeans: Estimated Marginal Means, Aka Least-Squares Means (version R package version 1.4.5). https://CRAN.R-project.org/package=emmeans.

Levon, Erez \& Isabelle Buchstaller. 2015. Perception, cognition and linguistic structure: The Effect of linguistic modularity and cognitive style on sociolinguistic processing. Language Variation and Change 27(3). 319-348.

Levon, Erez \& Susan Fox. 2014. Salience and the sociolinguistic monitor: A case study of ING and TH-Fronting in Britain'. Journal of English Linguistics 42(3). 185-217.

Levon, Erez \& Yang Ye. 2020. Language, indexicality and gender ideologies: Contextual effects on the perceived credibility of women. Gender and Language 14(2). 123-151.

Levon, Erez, Devyani Sharma \& Dominic Watt. 2017-2021. Accent bias and fair access in Britain. UK Economic and Social Research Council (Grant ES/P007767/1). https://accentbiasbritain.org/

Levon, Erez, Devyani Sharma \& Dominic Watt. 2020. Accent bias and fair access in Britain 2017-2021. [data collection]. UK Data Service. SN: 854405, http://doi.org/10.5255/UKDA-SN-854405. 
Levon, Erez, Devyani Sharma, Yang Ye, Amanda Cardoso \& Dominic Watt. 2021. Nested language ideologies: Does context affect accent bias? Paper presented at Sociolinguistics Symposium 23, University of Hong Kong, Hong Kong.

Linville, Patricia \& Gregory Fischer. 1993. Exemplar and abstraction models of perceived group variability and stereotypicality. Social Cognition 11(1). 92-125.

Llamas, Carmen, Dominic Watt \& Daniel Ezra Johnson. 2009. Linguistic accommodation and the salience of national identity markers in a border town. Journal of Language and Social Psychology 28(4). 381-407.

Mason, Rowena. 2013. David Cameron admits ministers must "do far more" to increase social mobility'. The Guardian. 14 November.

McCambridge, Jim, Marijn de Bruin \& John Witton. The effects of demand characteristics on research participant behaviours in non-laboratory settings: A systematic review. PLoS One 7(6). e39116.

Milroy, James \& Lesley Milroy. 1985. Authority in language: Investigating language prescription and standardisation. London: Routledge.

Montgomery, Chris \& Emma Moore. 2018. Evaluating S(c)Illy voices: The Effects of salience, stereotypes, and co-present language variables on real-time reactions to regional speech. Language 94(3). 629-661.

Mugglestone, Lynda. 2007. Talking proper: The rise of accent as social symbol. Oxford: Oxford University Press.

Nayakakuppam, Dhananjay, Joseph Priester, Jae Hwan Kwon, Leigh Anne Novak Donovan \& Richard Petty. 2018. Construction and retrieval of evaluative judgments: The attitude strength moderation model. Journal of Experimental Social Psychology 76. 54-66.

Office of National Statistics. 2011. Census 2011: Sex by age by national statistics socioeconomic classification (NS-SeC). 
Pantos, Andrew \& Andrew Perkins. 2012. Measuring implicit and explicit attitudes toward foreign-accented speech. Journal of Language and Social Psychology 32(1). 3-20.

Powesland, Peter \& Howard Giles. 1975. Persausiveness and accent-message incompatibility. Human Relations 28(1). 85-93.

R Core Team. 2019. R: A Language and Environment for Statistical Computing. Vienna: R Foundation for Statistical Computing.

Rakić, Tamara, Melanie Steffans \& Amélie Mummendey. 2011. When it matters how you pronounce it: The influence of regional accents on job interview outcome. British Journal of Psychology 102(4). 868-883.

Ray, George \& Christopher Zahn. 1990. Regional speech rates in the United States: A preliminary analysis. Communication Research Reports 7(1). 34-37.

Roberts, Celia, Evelyn Davies \& Thomas Cyprian Jupp. 1992. Language and discrimination: A study of communication in multi-ethnic workplaces. London: Longman.

Sankoff, Gillian \& Hélène Blondeau. 2007. Language change across the lifespan: /r/ in Montreal French'. Language 83(3). 560-588.

Savage, Mike, Fiona Devine, Niall Cunningham, Mark Taylor, Yaojun Li, Johs Hjellbrekke, Brigitte Le Roux, Sam Friedman \& Andrew Miles. 2013. A new model of social class? Findings from the BBC's Great British Class Survey Experiment. Sociology 47(2). 219250.

Sharma, Devyani, Erez Levon \& Yang Ye. in press. 50 years of British accent bias: Stability and lifespan change in attitudes to accents. English World-Wide.

Shaw, George Bernard. 1916. Pygmalion. New York: Brentano.

Simpson, Brent \& Henry Walker. 2002. Status characteristics and performance expectations: A reformulation'. Sociological Theory 20(1). 24-40. 
Social Mobility Commission. 2019. State of the nation 2018-19: Social mobility in Great Britain.

Social Mobility Commission. 2020. Monitoring social mobility 2013-2020.

Stephens, Nicole, Sarah Townsend \& Andrea Dittmann. 2019. Social-class disparities in higher education and professional workplaces: The role of cultural mismatch. Current Directions in Psychological Science 28(1). 67-73.

Strycharczuk, Patrycja, Manuel López-Ibáñez, Georgine Brown \& Adrian Leemann. 2020. General Northern English: Exploring regional variation in the North of England with machine learning. Frontiers in Artificial Intelligence 3. 48.

Stuart-Smith, Jane, Claire Timmins \& Farhana Alam. 2011. Hybridity and ethnic accents: A sociophonetic analysis of "Glaswasian”". In Frans Gregersen, Jeff Parrott, and Pia Quist (eds.) Language variation - European perspectives III: Selected papers from the 5th International Conference on Language Variation in Europe (ICLaVE 5), 43-57. Amsterdam: John Benjamins Publishing Company.

Swift, Jonathan. 1712. A proposal for correcting, improving and ascertaining the English tongue. London: Benj. Tooke.

Tagliamonte, Sali \& Alexandra D’Arcy. 2009. Peaks beyond phonology: Adolescence, incrementation, and language change. Language 85(1). 58-108.

The Sutton Trust \& Social Mobility Commission. 2019. Elitist Britain.

Toynbee, Polly. 2011. The class ceiling. BBC Radio 4.

Trudgill, Peter. 1974. The social differentiation of English in Norwich. Cambridge: Cambridge University Press.

Wagner, David, Rebecca Ford \& Thomas Ford. 1986. Can gender inequalities be reduced? American Sociological Review 51(1). 47-61. 
Wakeling, Paul \& Mike Savage. 2015. Entry to elite positions and the stratification of higher education in Britain. The Sociological Review 63(2). 290-320.

Watson, Kevin \& Lynn Clark. 2013. How salient is the NURSE SQUARE merger?' English Language and Linguistics 17(2). 297-323.

Watt, Dominic. 2002. “I don’t speak with a Geordie accent, I speak, like, the Northern accent": Contact-induced levelling in the Tyneside vowel system. Journal of Sociolinguistics 6(1). 44-63.

Webster, Murray \& James Driskell. 1978. Status generalization: A review and some new data. American Sociological Review 43(2). 220-236.

Wood, Martin, Jon Hales, Susan Purdon, Tanja Sejersen \& Oliver Hayllar. 2009. A test for racial discrimination in recruitment practice in British cities. Department for Work and Pension Research Report 607. 
TABLE 1. Examples of distinctive features across the five accents tested

\begin{tabular}{|c|c|c|c|c|c|c|c|}
\hline & FOOT/STRUT & BATH/TRAP & FACE & GOAT & happY & TH-fronting & /1/-vocalistion \\
\hline $\mathbf{R P}$ & split & split & $\operatorname{diph}[\mathrm{eI}]$ & $\operatorname{diph}[\partial v]$ & [i] & none & rare \\
\hline EE & split & split & $\operatorname{diph}[\Lambda \mathrm{I}]$ & $\operatorname{diph}[ə \mathrm{y}]$ & [əi] & $\mathrm{TH} / \mathrm{DH}$ & frequent \\
\hline MLE & split & split & monoph [e:] & monoph [o:] & [i:] & $\mathrm{TH} / \mathrm{DH}$ & occurs \\
\hline GNE & merged to /ə/ & merged & narrow diph & monoph/diph & [i] & none & none \\
\hline UWYE & merged to $/ \mathrm{J} /$ & merged & monoph $[\varepsilon:]$ & monoph [0:] & {$[\mathrm{i}] /[\mathrm{I}]$} & TH/DH & none \\
\hline
\end{tabular}


TABLE 2. Demographic distribution of respondents

\begin{tabular}{|c|c|c|c|}
\hline & $\mathrm{N}$ & $\%$ & $\begin{array}{l}\text { Median Class Index } \\
\quad \text { (range: } 1-9)\end{array}$ \\
\hline \multicolumn{4}{|l|}{ Gender } \\
\hline woman & 436 & 51.4 & 6.5 \\
\hline $\operatorname{man}$ & 411 & 48.5 & 5.25 \\
\hline prefer not to say & 1 & 0.1 & 4.25 \\
\hline \multicolumn{4}{|l|}{ Ethnicity } \\
\hline White & 746 & 88.0 & 5.75 \\
\hline Black & 18 & 2.1 & 6.38 \\
\hline South Asian & 30 & 3.5 & 6.0 \\
\hline East Asian & 18 & 2.1 & 7.0 \\
\hline Mixed/Other & 19 & 2.2 & 6.75 \\
\hline prefer not to say & 17 & 2 & 6.0 \\
\hline \multicolumn{4}{|l|}{ Region } \\
\hline Northern England & 237 & 28.0 & 5.75 \\
\hline Midlands & 159 & 18.8 & 5.25 \\
\hline Southern England & 452 & 53.3 & 6.0 \\
\hline
\end{tabular}


TABLE 3. Evaluation scales

On a scale of 1 to 10 (where 1 means 'Poor' and 10 means 'Excellent'), how would you rate the overall quality of the candidate's answer?

Does the candidate's answer show expert knowledge? $(1=$ Not at all; $10=$ Very much $)$

In your opinion, how likely is it that the candidate will succeed as a lawyer? $(1=$ Not at all likely; 10 = Very likely)

Is the candidate somebody that you personally would like to work with? $(1=$ Not at all; $10=$ Very much)

How would you rate the candidate overall? $(1=$ Poor; $10=$ Excellent $)$ 
TABLE 4. Fixed-effects predictors for regression modelling

\section{Predictor}

Accent

Question Type

Respondent Region

Respondent Age

Respondent Social Class Index

Respondent Motivation to Control Prejudiced Response

\section{Levels}

RP, GNE, UWYE, EE, MLE

expert, non-expert

South, Midlands, North

continuous (centred)

continuous (centred)

continuous (centred) 
TABLE 5. Summary of significant constraints on accent evaluations in England

\section{Constraint Pattern}

Age

Older respondents $(>45)$ rate Southern working-class varieties lower

Region Downgrading of Southern working-class accents by respondents in South and, to lesser extent Midlands; No evaluative differences for listeners in North

Expertise Questions requiring legal expertise evaluated more positively than questions about generic professional skills (significant interaction with region and accent)

MCPR Individual desire not to appear prejudiced positively correlates with evaluations (significant interaction with region and accent)

\section{Interpretation}

Enhanced socialisation into traditional workplace norms

Differences in in-group vs. out-group perceptions of accents and/or exposure to varieties; Gate-keeping attitudes by older Southern and Midlands listeners

Expertise serves as cue to specific status characteristic, mitigating accent bias

Psychological trait that mitigates accent bias 


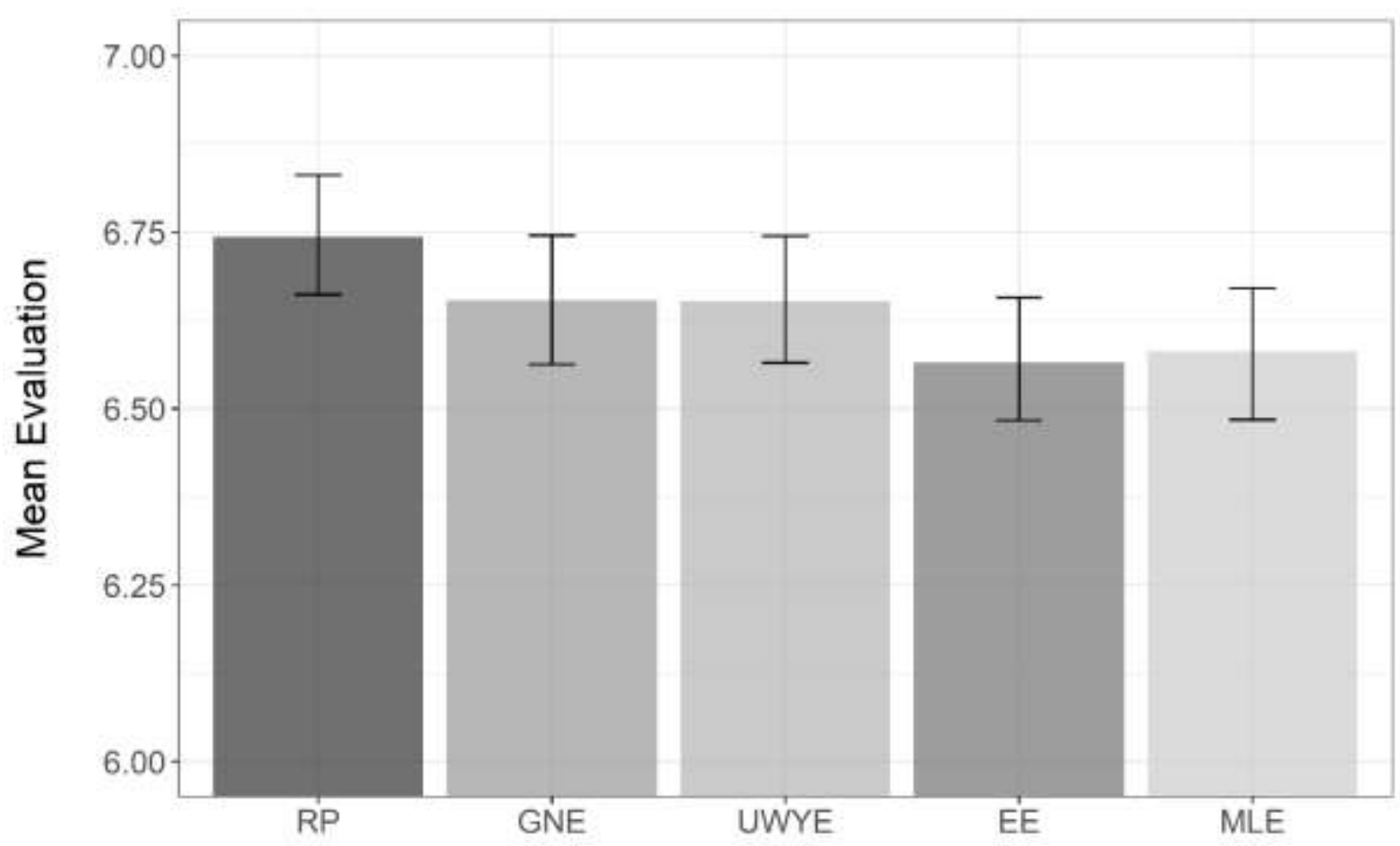

Figure 1: Mean Accent Evaluations in England $(\mathrm{N}=848)$ 


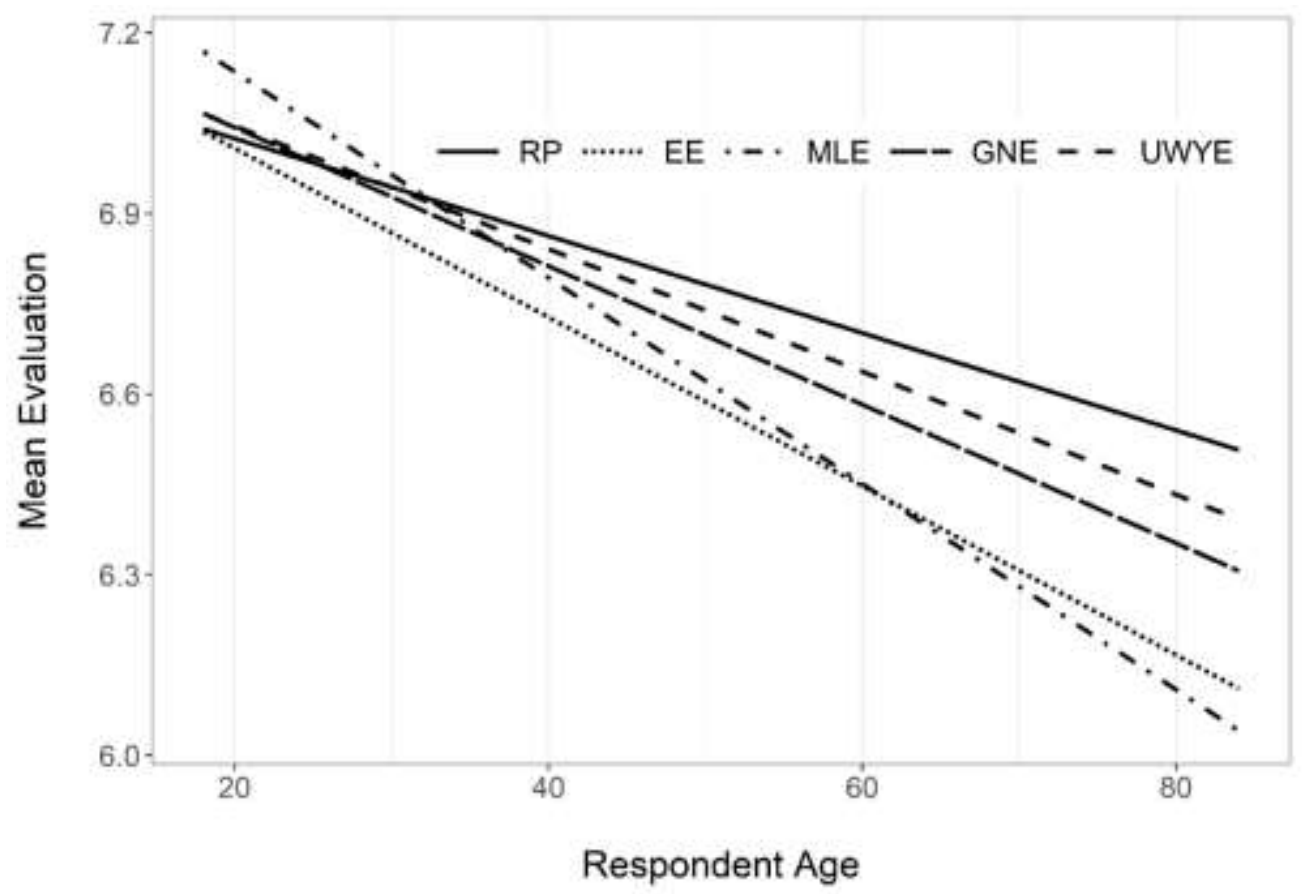

Figure 2: Accent Evaluations by Age (Model Predicted Values) 


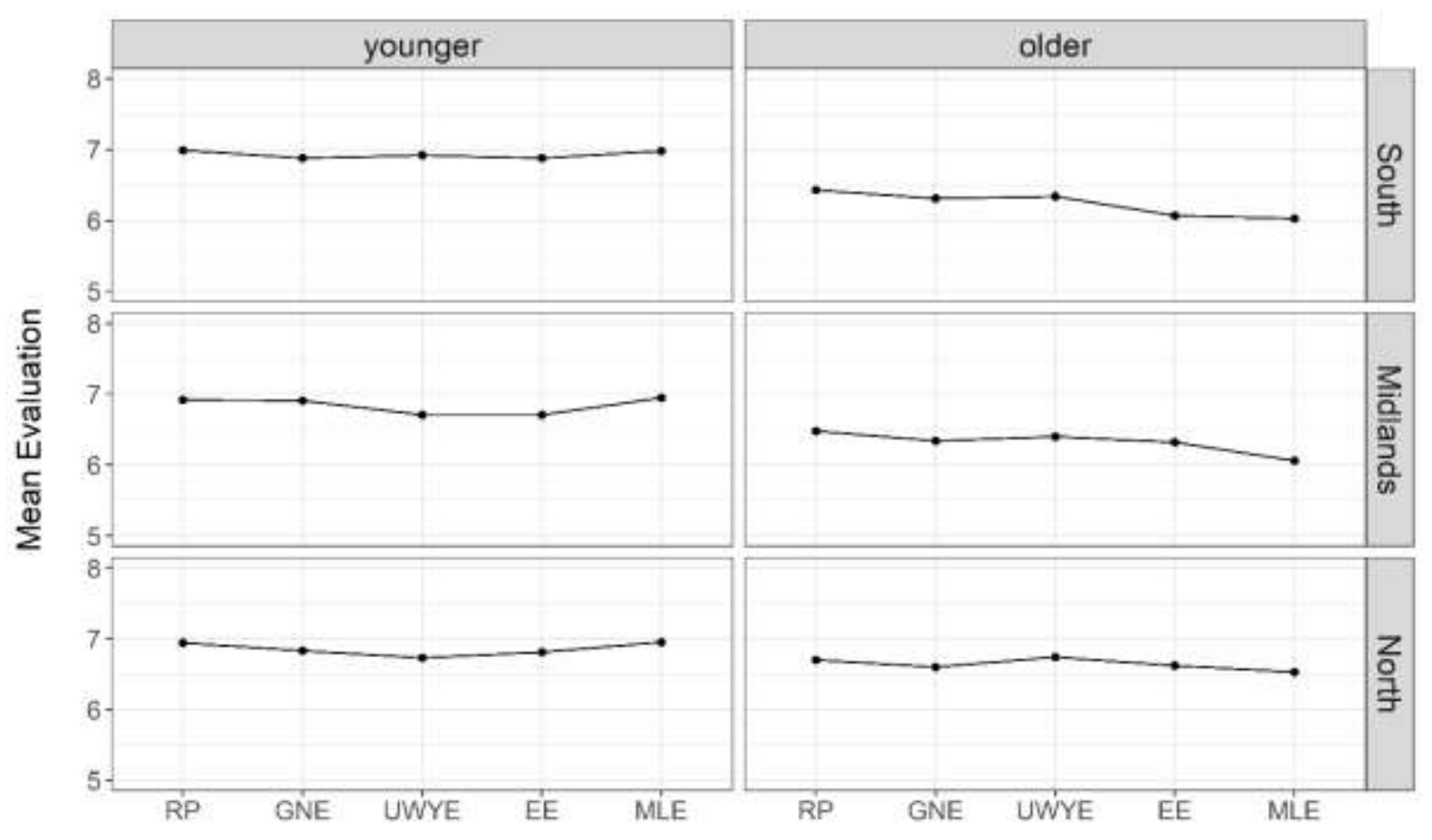

Figure 3: Accent Evaluations by Age and Region (Model Predicted Values) 


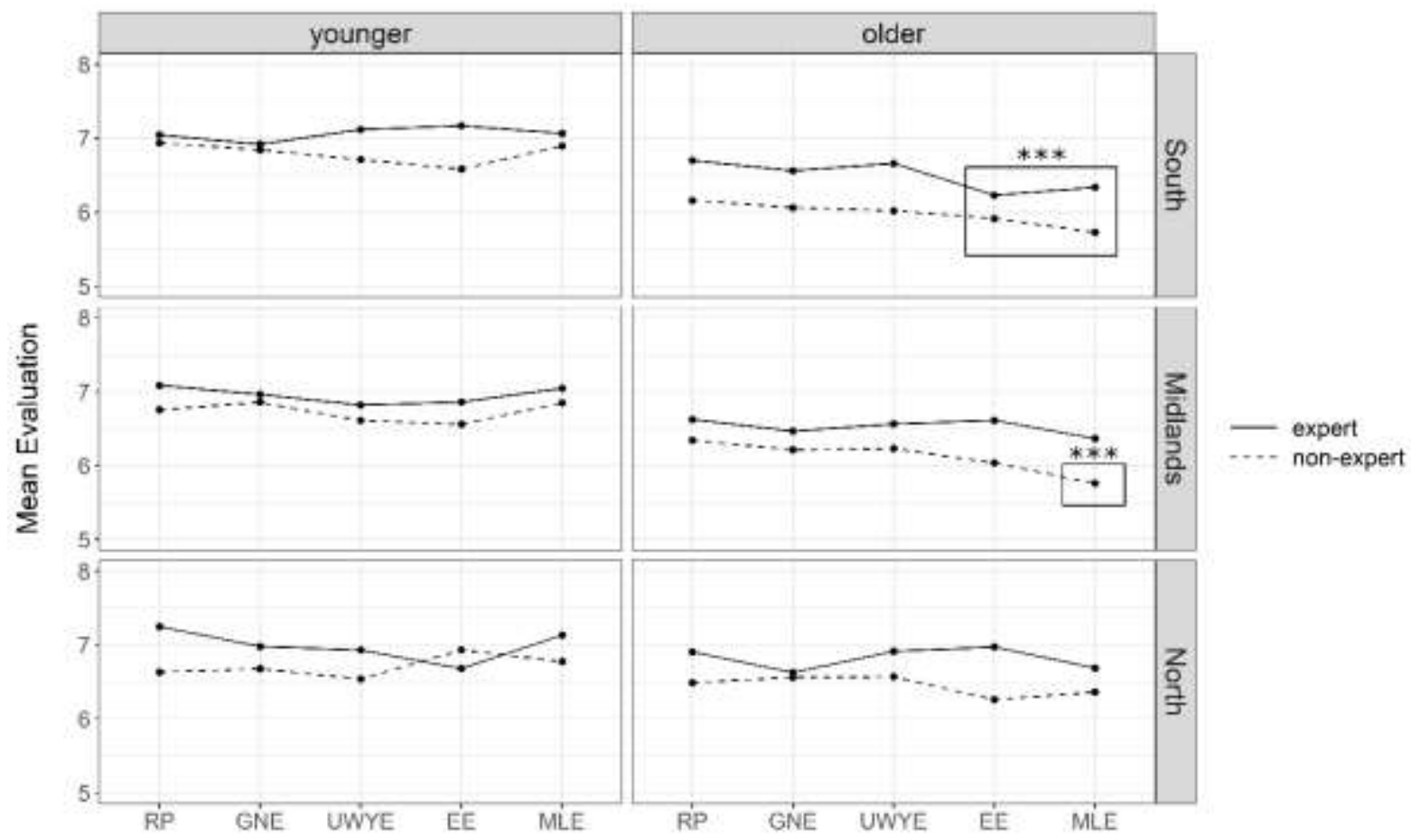

Figure 4: Accent Evaluations by Age, Region and Question Type (Model Predicted Values).

Boxes and asterisks indicate a significant difference between RP and a given accent in that condition. 


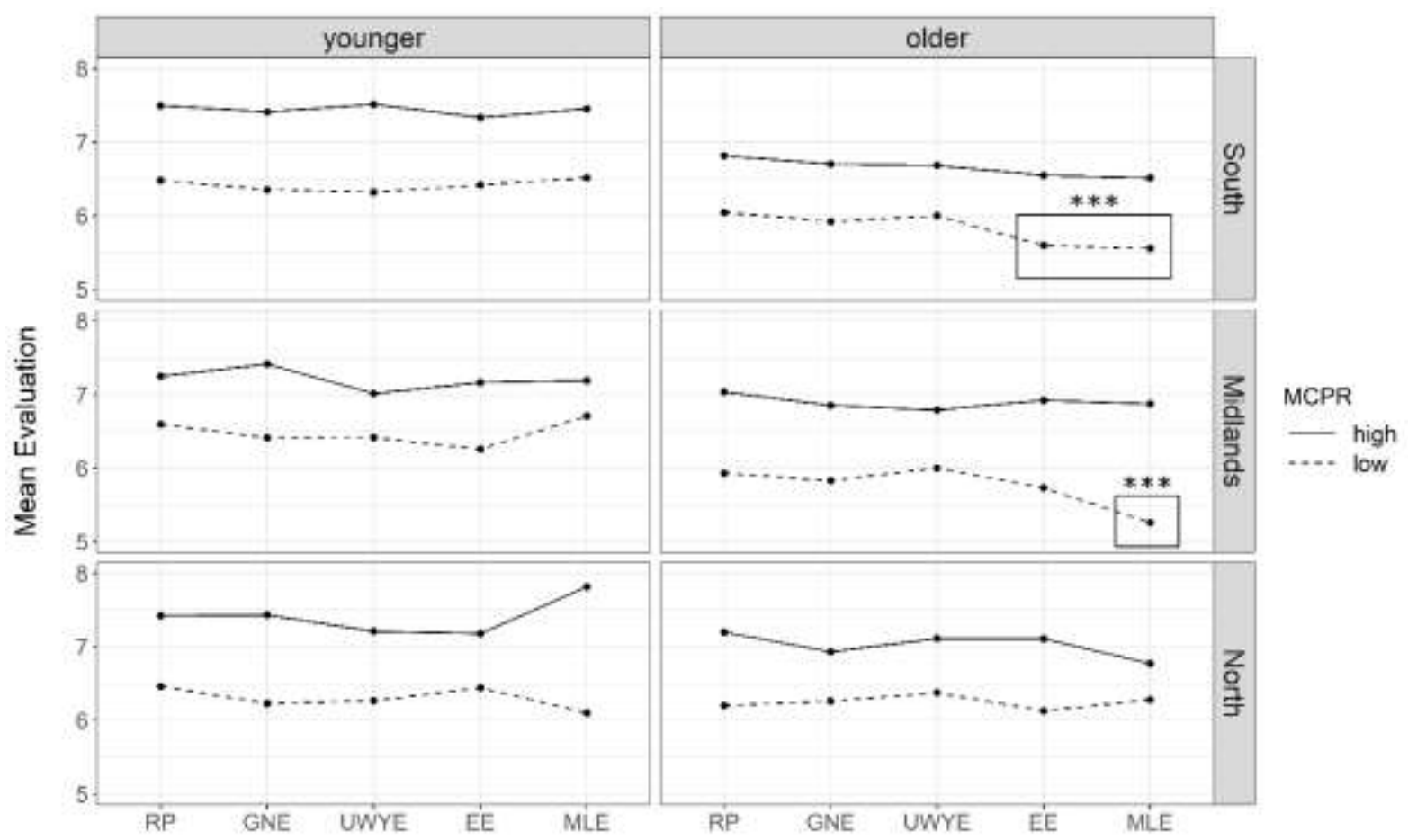

Figure 5: Accent Evaluations by Age, Region and Motivation to Control Prejudiced Response (Model Predicted Values). Boxes and asterisks indicate a significant difference between RP and a given accent in that condition. 